\title{
THE ROLE OF EARLY HAEMOPERFUSION/HAEMODIALYSIS WITH STEROIDS, CYCLOPHOSPHAMIDE, N ACETYL CYSTEINE AND EVEROLIMUS IN ACUTE PARAQUAT POISONING: IS THERE STILL HOPE?
}

\author{
Rajesh Waikhom1, Pukhrambam Vedanti2, Yumnam Iboton ${ }^{3}$, Ningombam Buddhachandra ${ }^{4}$, Khundrakpam Yohenba ${ }^{5}$ \\ ${ }_{1}^{1}$ Assistant Professor of Nephrology, Department of Medicine, Jawaharlal Nehru Institute of Medical Sciences, Porompat. \\ ${ }^{2}$ Assistant Professor, Department of Medicine, Jawaharlal Nehru Institute of Medical Sciences, Porompat. \\ ${ }^{3}$ Professor \& HOD, Department of Medicine, Jawaharlal Nehru Institute of Medical Sciences, Porompat. \\ ${ }^{4}$ Staff Medical Officer, Incharge of Dialysis Unit, Raj Medicity, Imphal. \\ ${ }^{5}$ Senior Resident, Department of Medicine, Jawaharlal Nehru Institute of Medical Sciences, Porompat.
}

\section{ABSTRACT}

\section{BACKGROUND}

Acute Paraquat poisoning is associated with very high mortality rate. There are no standardized treatment protocols and no effective antidote.

\section{AIMS}

In the absence of an effective antidote, early removal of paraquat by haemoperfusion/haemodialysis and addition of immunosuppressive agents, anti-oxidants and anti-fibrotic agents to counter the effect of paraquat may be beneficial. We present our experience of using Haemoperfusion/Haemodialysis in combination with pulse steroids, intravenous cyclophosphamide $\mathrm{N}$ Acetylcysteine infusion and Everolimus in such patients.

\section{MAIN METHODS AND RESULTS}

This study is conducted in two phases, during the first phase, the patients with paraquat poisoning are treated by the physicians as done in usual practice. In the second phase, standardized protocols were followed and patients received either early Haemoperfusion or Haemodialysis along with steroids, cyclophosphamide, $\mathrm{N}$ acetyl cysteine and Everolimus. We noted that with the use of standardized treatment protocol, the survival rate of severe paraquat poisoning has increased from $8 \%$ to $45.8 \%$.

\section{CONCLUSION}

Early Haemoperfusion/haemodialysis when used in combination with steroids, Cyclophosphamide, $\mathrm{N}$ acetyl infusion and Everolimus may be an effective treatment strategy in patients with severe paraquat poisoning.

\section{KEYWORDS}

Paraquat, Haemoperfusion, Everolimus.

HOW TO CITE THIS ARTICLE: Waikhom R, Vedanti P, Iboton Y, et al. The role of early haemoperfusion/haemodialysis with steroids, cyclophosphamide, $n$ acetyl cysteine and everolimus in acute paraquat poisoning: is there still hope? J Evolution Med Dent Sci 2016;5(5):272-274, DOI: 10.14260/jemds/2016/58

\section{INTRODUCTION}

Paraquat is a highly toxic herbicide wisely used in agricultural industries. This continues to be used in many Asian countries, pacific nations and even in the developed countries. Paraquat gets concentrated inside cells and undergoes redox cycling thereby generating superoxide radicals which is a highly reactive oxygen species and can cause cellular damage via lipid peroxidation, activation of nuclear factor Kappa B, damaging the mitochondria and apoptosis. Paraquat ingested gets concentrated in lungs, liver, kidney, heart and other organs. Paraquat poisoning is usually associated with pneumonitis, lung fibrosis, Acute Kidney Injury, liver function derangement in addition to the local irritating effect. Swallowing of more than $30 \mathrm{ml}$ of $20-24 \%$ (w/v) Paraquat formulation is typically lethal.[1] Paraquat poisoning continues to be a major health problem in both developing as well as developed countries. Paraquat was withdrawn from European Union market in 2007.

Financial or Other, Competing Interest: None.

Submission 01-01-2016, Peer Review 04-01-2016,

Acceptance 11-01-2016, Published 16-01-2016.

Corresponding Author:

Dr. Rajesh Waikhom,

Department of Medicine,

Jawaharlal Nehru Institute of Medical Sciences,

Porompat.

E-mail: rajesh.waikhom@gmail.com

DOI:10.14260/jemds/2016/58
No effective antidote has been identified for Paraquat poisoning. It is generally believed that once systemic toxicity manifestations have appeared then intensive care does not improve the outcomes. The presence of tachypnea, hypoxia on room air, refractory hypotension, mediastinitis, severe metabolic acidosis and development of Acute Kidney Injury are considered as ominous signs. The treatment regime may also vary from Centre to Centre and there are no standardized guidelines to help in decision making. In this paper we highlight our experience with respect to management of paraquat poisoning and the changes in the survival outcome noted in our Centre after following a standardized protocol.

\section{MATERIALS AND METHODS}

This is a prospective study carried out in two tertiary referral centres in city of Imphal in north eastern part of India. All patients with suicidal intent use of paraquat who presented to the above mentioned two referral centre's namely Department Of Medicine at Jawaharlal Nehru Institute of Medical Sciences, Porompat and Department of Medicine at Raj Medicity, from October 2012 to September 2015 were included in this study. Informed consent were taken from the patient and accompanying relatives in all cases. The study was approved by the Ethical committee of both the institute.

The amount of paraquat ingested was assessed as per the patients or eye witness description. 
Degree of poisoning was assessed as per number of mouthful $(20 \mathrm{ml})$ of paraquat concentrate ingested. Consumption of more than two mouthful was considered as severe poisoning while those consuming one mouthful was considered as moderate. The amount of paraquat left in the bottle whenever brought was also used to correlate with the description. From October 2012 till June 2013, Patient with paraquat poisoning were treated with IV cyclophosphamide, Pulse methyl Prednisolone and Haemodialysis support for Acute Kidney Injury along with other supportive treatment measures.

This was the trend of practice generally followed during that time. There was no fixed protocol and the dosage of methyl Prednisolone and Cyclophosphamide used varied depending upon physicians choice. From July 2013 onwards, there was a change in the management protocol. Those patients who presented within 6 hours of ingestion were subjected to Charcoal Haemoperfusion/Haemodialysis. In addition, the following specific treatments were given.

IV Methyl Prednisolone $1 \mathrm{~g}$ X 3 days followed by IV Dexamethasone $20 \mathrm{mg}$ daily for 2 weeks.

IV Cyclophosphamide $500 \mathrm{mg} / \mathrm{m} 2$ for 2 days.

$\mathrm{N}$ acetyl infusion-20gram over 24 hours.

Tablet Everolimus $0.25 \mathrm{mg} 12$ hourly for 2 weeks.

Haemoperfusion was done using Prismaflex Adsorba $300 \mathrm{Kit}$ for a period of 8 hours. The procedure was performed using a double lumen femoral catheter with blood flow set at $200 \mathrm{ml} /$ minute. Those who cannot afford haemoperfusion were subjected to haemodialysis for 8 hours. All patients at admission were subjected to laboratory work up -Blood haemogram, Renal Function, Arterial blood gas analysis, Liver Function test, Serum electrolytes, Chest X-ray were done at entry. CT scan chest was done as and when required. Statistical analysis were performed using Graph Pad software. The data were calculated for mean with standard deviations, median. Fisher's exact test was used for analysing the categorical variables. A p value of $<0.005$ was considered statistically significant.

\section{RESULTS}

Thirty six patients were included in this study. There were 12 patients in the first group (Study period October 2012 to June 2013) and 24 patients in the second group (July 2013 to September 2015). The overall mean age of the patients were $28.69+/-7.56$ years (Range 17-42 years). The mean volume of paraquat ingested were $60.41+/-44.4$ (Range 20-250) $\mathrm{ml}$. The overall median time of presentation was 6.5 hours (Range 2 hours to 90 hours).

The clinical pictures of these patients at presentation include restlessness, shortness of breath, inability to swallow, drooling of saliva due to odynophagia, oral lesions. Two of the patients died immediately after admission and no investigation reports were available.

\section{Renal Involvement}

Acute Kidney Injury was noted in 30 (83.3\%) of these patients. Haemodialysis were required for the acute kidney injury in 23 of them. For those who survived the renal recovery was complete and normalized in all. The renal recovery usually occurs by the end of the first week.

\section{Hepatic Involvement}

Hepatic involvement in form of elevated bilirubin and elevated liver enzymes were noted in 23 (63.8\%) patients.
However, recovery do occur and for the survivors all of them had normal liver function at discharge.

\section{Lung Involvement}

The most common cause of the late mortality ( $>1$ week of ingestion) noted in our patients were attributed to respiratory failure; 17 patients died after 1 week of consumption of paraquat and the cause of death were attributed to respiratory failure in 13 of these patients.

\section{Central Nervous System Features}

Features of central nervous system involvement in form of restlessness/altered sensorium were seen in presentation in two patients who had consumed large amount and such patients had very poor prognosis and died within few hours. The baseline characteristics and outcome of the patients are presented in Table 1.

\section{DISCUSSION}

Traditionally suicidal intent usage of paraquat poisoning is believed to be associated with a very high mortality. This high mortality rate discourages many physicians from being very aggressive in the management of paraquat poisoning. There are no fixed standardized protocol followed worldwide.[2] Similar sort of dilemma were noted during the first part of our study period. Each patient was managed by the physician as per his experience of handling such cases. The treatment regimes varied considerably and the dosage of the immunesuppressant also varied.

In the first part of the study, it can be noted that there was a very high mortality rate $(91.7 \%)$. This may be comparable to some studies and higher compared to others.[3],[4] Many factors may be responsible for this. Firstly many of the patients presented late. The mean time to presentation was $9.63+/-12.19$ hours and only $50 \%$ of the patients presented within 6 hours. One reason for such a late presentation is late referral from peripheral centres and rural areas. Many physicians might tend to think that there is not much one can do once someone has consumed paraquat. The importance of early removal of toxin might be undermined. Secondly, the mean dosage of the volume of paraquat consumed in this group were quite high roughly around $63.7+/-34.3 \mathrm{ml}$. Consumption of more than $50 \mathrm{ml}-100 \mathrm{ml}$ of $20 \%$ ion/weight of paraquat is known to cause fulminant organ failure and death.[2]

The dismal survival rate prompted us to review the management protocol and look for any form of treatment which can improve the survival. We started using extra corporeal therapy for toxin removal if the patient presented to us within 6 hours of consumption. Charcoal haemoperfusion was the preferred modality and to those patients who could not afford haemoperfusion, haemodialysis was used as treatment option. The survival advantage of early haemoperfusion following paraquat exposure has been addressed in various studies.[5],[6] 8 patients received Haemoperfusion while 14 patients received early Haemodialysis for toxin removal.2 patients died before extracorporeal therapy could be initiated. Pulse steroids and cyclophosphamide are generally given to reduce the inflammation process in the lung following paraquat ingestion.

In a systematic review by $\mathrm{Li}$ et al.[7] administration of glucocorticoids with cyclophosphamide had a lower risk of death (RR 0.72) compared to those who received standard 
care alone. Similar survival benefits were also noted in the meta analysis by $\mathrm{He}$ et al.[8] The beneficial effect of combination of immunosuppressive with haemoperfusion and their survival benefits have also been addressed earlier. In the nationwide analysis by $\mathrm{Wu}$ et al, the addition of immunosuppressive therapy to Haemoperfusion for paraquat poisoning increased the survival rate from $24.2 \%$ to $29.3 \%$. The usage of methylprednisolone, cyclophosphamide and dexamethasone in addition to haemoperfusion was associated with the highest survival rate of $48 \%$. $^{[3]}$ Mtor inhibitors are known to have anti proliferative effect on fibroblasts and lymphoid and non-lymphoid tumour cells. (9) The mechanism of inhibition of inflammatory responses by mtor inhibitors may be different from that of cyclophosphamide and steroids. The role of mtor inhibitors sirolimus in patients with severe acute paraquat poisoning has been published earlier as case reports by Barrueto et al.[10] and Lorenzen et al.[11] with conflicting results.

With the usage of extracorporeal therapy (Haemoperfusion/Haemodialysis) in combination with immunosuppressive agent (Glucocorticoids, cyclophosphamide), anti-oxidant (N Acetyl Cysteine) and antifibrotic agents (Everolimus), we have been able to bring down the mortality rate to $55 \%$. If we compare the patients in the two study period the baseline characteristics in terms of age, median time to presentation, mean volume of paraquat ingested are quite similar. A better management protocol, more aggressive approach could have resulted in the improved survival rate.

We also noted that those who had consumed large amount (Exceeding 100ml) and who had neurological manifestation at presentation rarely survive. Such group of patients may not benefit from all forms of therapy. The role of immunosuppressive therapy along with haemoperfusion is uncertain in such cases. Our study has many limitations. The study was primarily aimed at improving the patient outcomes and survival of those with acute paraquat poisoning. The number of patients included in this study are too small to make any definite recommendations. Secondly we have relied on the history of the amount of consumption and clinical pictures to assess the severity of the poisoning. We did not have the laboratory facility to get the paraquat level concentration for the patients. The volume of paraquat consumed as described by patients may at times be misleading. Thus to conclude, Although Paraquat poisoning is associated with a high mortality rate, it may be worthwhile in attempting early corporeal therapy (Haemoperfusion/haemodialysis) in combination with steroids, cyclophosphamide, Everolimus and $\mathrm{N}$ acetyl cysteine at least in those who present early and had consumed $<100 \mathrm{ml}$.

\begin{tabular}{|c|c|c|c|}
\hline & $\begin{array}{c}\text { First Study } \\
\text { Period }\end{array}$ & $\begin{array}{c}\text { Second } \\
\text { Study } \\
\text { Period }\end{array}$ & $\begin{array}{c}\text { P value } \\
(*<\mathbf{0 . 0 5} \\
\text { is } \\
\text { Signific } \\
\text { ant) }\end{array}$ \\
\hline Age (Years) Mean & $27.5+/-8.62$ & $\begin{array}{c}29.29+/- \\
7.09\end{array}$ & 0.514 \\
\hline Sex & $\begin{array}{c}4 \text { (Male) } \\
8 \text { (Female) }\end{array}$ & $\begin{array}{c}8 \text { (Male) } \\
16 \text { (Female) }\end{array}$ & \\
\hline $\begin{array}{c}\text { Time to presentation } \\
\text { (Hrs.) }\end{array}$ & $9.63+/ 12.19$ & $\begin{array}{c}12.2+/- \\
21.44\end{array}$ & 0.7032 \\
$\begin{array}{c}\text { Mean time } \\
\text { Median time }\end{array}$ & 6.5 hours & 6.5 hours & \\
\hline $\begin{array}{c}\text { Number of patients who } \\
\text { presented within 6 hours }\end{array}$ & $6 / 12(50 \%)$ & $\begin{array}{c}12 / 24 \\
(50 \%)\end{array}$ & \\
\hline
\end{tabular}

\begin{tabular}{|c|c|c|c|}
\hline $\begin{array}{c}\text { Intake volume (ml) Mean } \\
\text { Those who survived } \\
\text { Those who did not } \\
\text { survived }\end{array}$ & $\begin{array}{c}63.7+/-34.3 \\
30\end{array}$ & $\begin{array}{c}53.33+/- \\
46.7\end{array}$ & 0.49 \\
$78.6+/-35.92$ & $70.7+/-$ & 0.69 \\
\hline $\begin{array}{c}\text { Number of patients who } \\
\text { received }\end{array}$ & None & 8.23 & \\
$\begin{array}{c}\text { Early Haemoperfusion } \\
\text { Early Dialysis }\end{array}$ & None & 14 & \\
\hline $\begin{array}{c}\text { Number of patients who } \\
\text { survived }\end{array}$ & $1(8 \%)$ & $11(45.8 \%)$ & $\begin{array}{c}\text { Two } \\
\text { tailed P } \\
\text { value } \\
\text { Total 12 (33.3\%) }\end{array}$ \\
\hline \multicolumn{2}{|c|}{ Table 1: Table showing the subgroup } \\
\hline \multicolumn{2}{|c|}{ analysis and the outcome of the patients } \\
\hline
\end{tabular}

\section{REFERENCES}

1. Wilks MF, Tomenson JA, Fernando R, Ariyananda PL, Berry DJ, Buckley NA, et al. Formulation changes and time trends in outcome following paraquat ingestion in Sri Lanka Clin Toxicol (Phila) 2011 Jan;49(1):21-8.

2. Indika B Awarammana, Nicholas A Buckley. Medical management of paraquat ingestion. Br J Clin Pharmacol 2011 Nov; 72(5):745-757.

3. Wen Pyng Wu, Ming Nan Lai, Ching Heng Lin, Yu Fen Li, Ching Yuang Lin, Ming Ju Wu. Addition of immunosuppressive treatment to haemoperfusion is associated with improved survival after paraquat poisoning: A Nationwide Study. PLoS One 2014;9(1):e87568.

4. Mohammad Delirrad, Mohammad Majidi, Behzad Bousheri. Clinical features and prognosis of paraquat poisoning: a review of 41 cases. Int J Clin Exp Med 2015:8(5):8122-8128.

5. Hsu CW, Lin JL, Lin Tan DT, Chen KH, Yen TH, Wu MS, et al. Early haemoperfusion may improve survival of severely paraquat poisoned patients. PLoS One 2012;7(10):e48397.

6. Gao Y, Zhang X, Yang Y, et al. Early haemoperfusion with continuous venovenous haemofiltration improves survival of acute paraquat poisoned patients. J Int Med Res 2015 Feb;43(1):26-32.

7. Li LR, Sydenham E, Chaudhary B, et al. Glucocorticoid with cyclophosphamide for paraquat induced lung fibrosis Cochrane Database Syst Rev 2014 Au 7;8:CD008084.

8. He F, Xu P, Zhan J, Zhang Q, Gu S, Liu Y, et al. Efficacy and safety of pulse immunosuppressive therapy with glucocorticoid and cyclophosphamide in patients with paraquat poisoning: A metaanalysis. Int Immunopharmacol 2015 Jul; 27(1):1-7.

9. Sehgal SN. Rapamune (RAPA, rapamycin, sirolimus): mechanism of action immunosuppressive effect results from blockade of signal transduction and inhibition of cell cycle progression. Clin Biochem 1998;31:335-340.

10. Barrueto $F$, Lee $C$, Pajoumand $M$, et al. Use of sirolimus in a case of severe paraquat poisoning. Clinical Toxicology (Phila) 2008 Sep 46; ( 8):778-779.

11. John Matthes Lorenzen, Eva Schonenberer, Carsten Hafer, et al. Failed rescue therapy with rapamycin after paraquat intoxication Clin Toxicol (Phila). 2010 Jan;48(1)84-6. 